\title{
Composite of Poly(Dithienopyrrole) and Poly(Vinylchloride) \\ Obtained by the Electrode Coating Method
}

\author{
Marco-A. De Paoli ${ }^{a *}$, Giuseppe Casalbore-Miceli ${ }^{b}$, and Alessandro Geri ${ }^{b}$ \\ ${ }^{a}$ Laboratório de Polímeros Condutores, Instituto de Quimica, UNICAMP , C.P. 6154, \\ 13081-970 Campinas - SP, Brazil \\ ${ }^{b}$ Istituto di Fotochimica e Radiazioni d'Alta Energia del C.N.R., via Gobetti 101, \\ 40129 Bologna, Italy
}

Received: Junho 17, 1996

\begin{abstract}
Filmes compósitos obtidos pela polimerização eletroquímica de ditienopirrol sobre eletrodos de platina ou ITO recobertos com um filme de poli(cloreto de vinila) foram estudados neste trabalho. Os resultados obtidos da análise térmica e de microscopia indicam a natureza compósita do material. As propriedades eletrocrômicas foram estudadas por espectroeletroquímica dinâmica e são semelhantes às propriedades do poli(ditienopirrol) puro.

Composite films obtained by the electrochemical polymerization of dithienopyrrole onto poly(vinylchloride) coated platinum or ITO electrodes were prepared and studied in this work. Results obtained by thermal analysis and microscopy show the composite nature of the material. The electrochromic properties were studied by dynamic spectroelectrochemistry and resemble those of the pure poly(dithienopyrrole) polymer.
\end{abstract}

Keywords: conductive polymeric composite, electrochromism, thermoplastic

\section{Introduction}

Processability is a property important for polymeric materials in general and, particularly, for conducting polymers to make them technologically useful. A convenient route to render a conducting polymer with electro-optic properties usable for technological processes is by its inclusion in a film of a non conducting but processable host polymer ${ }^{1}$. The combinations of two or more polymers produce a blend if the product is homogeneous or a composite if it is heterogeneous. Electrochemical techniques were largely used for these purposes, and conductive polymers were included in films of polyvinylchloride $(\mathrm{PVC})^{2}$, nitrilic rubber $^{3}$, ethylene-propylene-diene rubber ${ }^{4}$ and many other processable polymeric materials ${ }^{5}$.

Preliminary results were reported in a previous paper describing the anodic polymerization of dithienopyrrole on films of $\mathrm{PVC}^{6}$. Adherent films cannot be obtained by the electrochemical polymerization of dithienopyrrole on different substrates. Nevertheless, an electrochemically deposited film of pure poly(dithienopyrrole), pDP, showed interesting electrochromic properties $^{6}$. Films of pDP deposited on PVC coated electrodes also showed electrochromic properties in comparison to the pure polymer. On the other hand, they did not characterize the new material in detail and consequently it was not clear whether it was a composite, a blend or a copolymer. Furthermore, they did not do morphological and thermal analysis for the determination of the stability and the composition of this polymeric material.

In this paper we report on results obtained by several techniques, which better explain the characteristics and the composition of the product obtained by the electropolymerization of dithienopyrrole on PVC films. We confirm the composite nature of the material and its electrochromic properties.

\section{Experimental}

4H-dithieno[3,2-b;2',3'-d]-pyrrole (dithienopyrrole) was synthesized as described in the literature ${ }^{8}$. Films of poly(dithienopyrrole) on PVC were prepared by cycling

*mdepaoli@iqm.unicamp.br 
ITO (glass slides coated with indium-tin oxide) electrodes coated with PVC films (thickness 2-7 $\mu \mathrm{m}$ ) between -0.5 and $\langle \%-2\rangle 1.5 \mathrm{~V}$ in acetonitrile solutions of dithienopyrrole $\left(1 \times 10^{-2} \mathrm{M}\right)$ and $0.1 \mathrm{M}$ tetrabutylammonium perchlorate (TBAP) or $0.1 \mathrm{M}$ tetrabutylammonium tetrafluorborate (TBAF). The electrode potentials in this work are referred to the saturated calomel electrode, moreover, a salt bridge was used to connect the reference electrode and the organic electrolyte solution.

Acetonitrile (Merck p.a.) was dehydrated with $\mathrm{CaCl}_{2}$, twice distilled over $\mathrm{CaH}_{2}$, and stored under nitrogen atmosphere. TBAP and TBAF were purified by crystallization from methanol.

Dynamic spectro-electrochemical experiments were carried out using an electrochemical cell with optically transparent windows in the sample compartment of an Hewlett-Packard 8452A diode-array spectrophotometer with a response time of $0.1 \mathrm{~s}$. The electrode potential was controlled with a FAC 200A potentiostat driven by a computer and a home made program. Cyclic-voltammetric experiments were done with an AMEL Electrochemolab instrument.

Thermogravimetry (TGA) determinations and the experiments of Differential Scanning Calorimetry (DSC) were performed with a Dupont 9900 Thermal Analysis system. The Fourier-transform infrared spectra were obtained with a FT-IR DX Nicolet instrument.

\section{Results and Discussion}

The cyclic voltammetries of dithienopyrrole dissolved in acetonitrile and of films of poly(dithienopyrrole)/PVC, pDP/PVC, are shown in Fig. 1. These were prepared on ITO electrodes, as described in the experimental part, both with $\mathrm{ClO}_{4}^{-}$and $\mathrm{BF}_{4}^{-}$as counterions. These were used to study the effect of anions with different ionic radius on the redox processes of the composite material. Curves $a$ and $b$ demonstrate the small interference of the anion of the electrolyte on the electrochemical properties of the monomer. Curve 1c clearly demonstrate that, the PVC matrix produces a strong broadening of the redox waves, probably caused by the hindrance for ion diffusion. The insulating host, however, does not hinder the reversibility of the redox process of $\mathrm{pDP}$.

The variation of the optical spectrum as a function of applied potential for a film of $\mathrm{pDP}\left(\mathrm{BF}_{4}{ }^{-}\right.$as counterion)/PVC on ITO electrode is reported in Fig. 2. The potential was scanned at $50 \mathrm{mV} \mathrm{s}^{-1}$ from 0 to $+1.5 \mathrm{~V}$ and then back to $0 \mathrm{~V}$ (in relation to $\mathrm{SCE}$ ). A good agreement is observed when comparing the spectra of Fig. 2 with

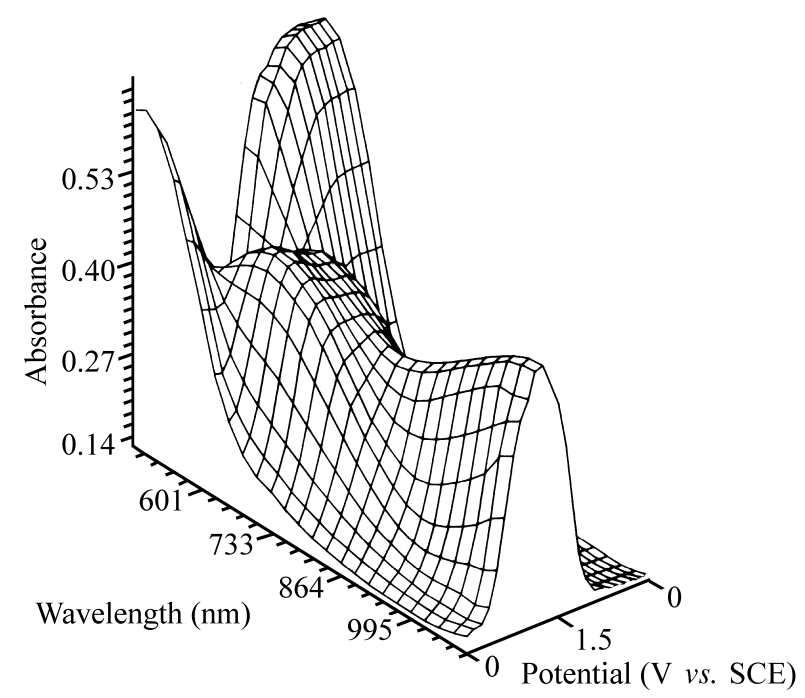

Figure 2. Variation of the absorbance spectra of a film of pDP on $\mathrm{PVC}(7 \mu \mathrm{m}$ thick $)$ as a function of electrode potential. Scan rate $=50$
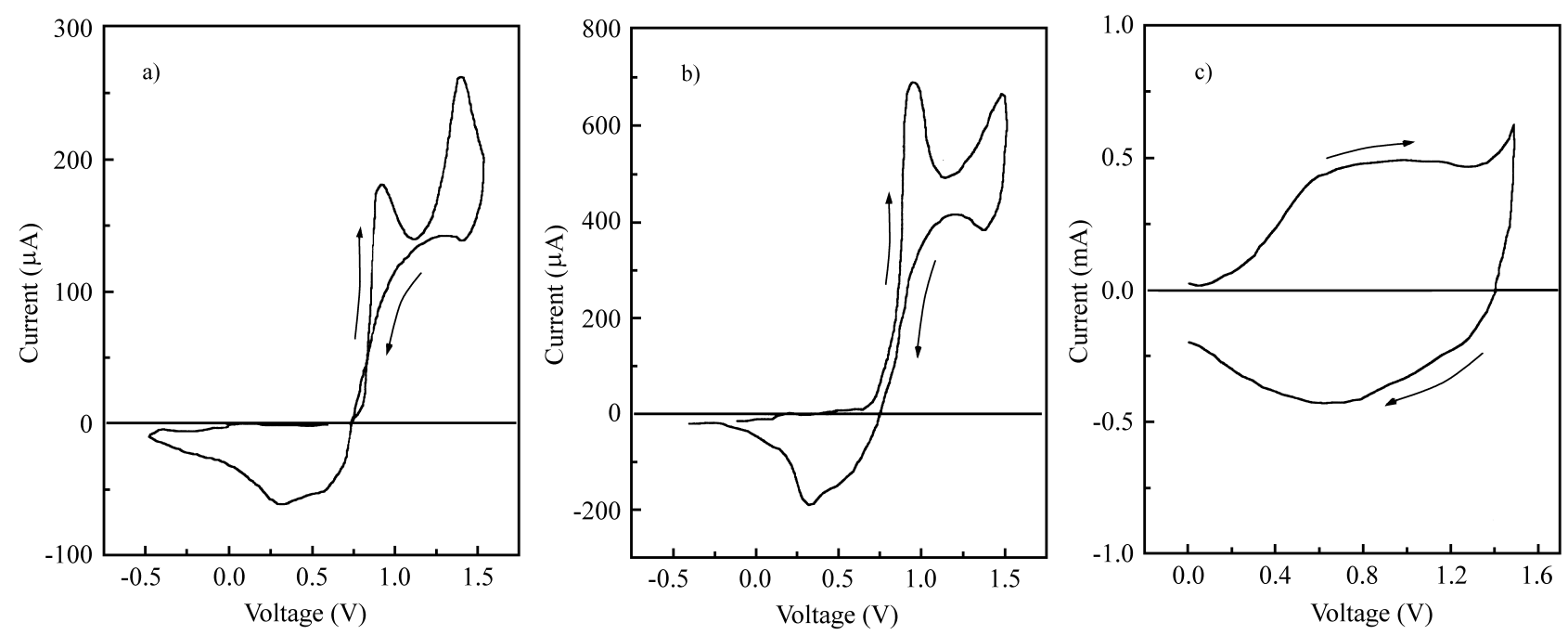

Figure 1. Cyclic voltammetries of $10 \mathrm{mM}$ solutions of dithienopyrrole in acetonitrile: a) TBAP $0.1 \mathrm{M}, \mathrm{b}$ ) TBAF as supporting electrolytes, and c) $0.7-0.8 \mu \mathrm{m}$ thick film of $\mathrm{pDP}$ on PVC coated Pt electrode. Scan rate $=50 \mathrm{mV} \mathrm{s}^{-1}$. 
those previously obtained at stationary conditions with a film of $\mathrm{pDP}\left(\mathrm{ClO}_{4}{ }^{-}\right.$as counterion $) / \mathrm{PVC}^{9}$. In these previous experiments, 2 or $3 \mathrm{~s}$ after the potential change, the equilibrium at the new condition was nearly reached, without evidence of intermediate species between the initial and final states. The redox process of the conductive polymer depend on the diffusion of ions between the polymer film and the electrolyte solution. The results obtained with $\mathrm{pDP} / \mathrm{PVC}$ is an indication that the hindrance to the ion diffusion process caused by the PVC phase is not sufficiently large to impede the optical response of the material. Moreover, the change of the counterion $\left(\mathrm{ClO}_{4}{ }^{-}\right.$in the stationary, $\mathrm{BF}_{4}^{-}$in the dynamic experiments) did not affect the electrochromic results. The dynamic experiments (measurement of the absorption spectra during a cyclic voltammetry scan) reveal intermediate absorptions at 650 $\mathrm{nm}$ under an applied potential of 1.3 to $1.4 \mathrm{~V}$ (in relation to SCE), in cathodic or anodic scan, Fig. 2. This absorption was also observed in the stationary experiments ${ }^{9}$. When the film is polarized at $1.5 \mathrm{~V}$ the absorption is lower producing a valley in this region of the curve, indicating a high chromatic contrast between the reduced and the oxidized species.

Thermogravimetric experiments on pure pDP samples, with $\mathrm{ClO}_{4}$ - and $\mathrm{BF}_{4}^{-}$as counterions, are reported in Figs. 3 and 4 , respectively. In both cases two different thermogravimetric steps are visible. The first one is assigned to dedoping of the polymer with a mass loss corresponding to counterion elimination. This step is centered at $232{ }^{\circ} \mathrm{C}$ in the case of $\mathrm{ClO}_{4}^{-}$, and badly defined but centered in the range $232-300{ }^{\circ} \mathrm{C}$ in the case of $\mathrm{BF}_{4}{ }^{-}$. The mass loss is $22.5 \%$ for $\mathrm{ClO}_{4}{ }^{-}$and $18 \%$ for $\mathrm{BF}_{4}^{-}$, respectively. These values can be correlated to the mass loss due to dedoping. Assuming a charge of $0.5-0.6 \mathrm{mC}$ per monomer unit (as determined previously for oxidized $\mathrm{pDP}^{6}$ ), total dedoping would lead to a theoretical mass loss of $22-25 \%$ for $\mathrm{pDP}\left(\mathrm{ClO}_{4}^{-}\right)$and $19-22 \%$ for $\mathrm{pDP}\left(\mathrm{BF}_{4}^{-}\right)$.

The second thermogravimetric step is due to decomposition of the polymer, and begins at $c a .600{ }^{\circ} \mathrm{C}$, for both composites. For these samples a mass decrease can be detected in the range from 60 to $80^{\circ} \mathrm{C}$. This mass loss decrease is not observed if the sample is previously heated to $100{ }^{\circ} \mathrm{C}$, and is assigned to solvent or $\mathrm{H}_{2} \mathrm{O}$ evaporation, as observed previously for other conducting polymers ${ }^{10,11}$.

Differential scanning calorimetry measurements, DSC, for $\mathrm{pDP} / \mathrm{ClO}_{4}{ }^{-}$reveal an endothermic process, not detectable in the second heating cycle, in the range from 60 to $80{ }^{\circ} \mathrm{C}$, due to the $\mathrm{H}_{2} \mathrm{O}$ or/and solvent evaporation and to a correlated rearrangement of the polymer chains, Fig. 5. An exothermic process in the range from 200 to $230^{\circ} \mathrm{C}$ is evident in the case of $\mathrm{ClO}_{4}{ }^{-}$doped polymer. It is assigned to the counterion loss, as demonstrated by the thermogravimetric experiments on the same sample. The loss of the $\mathrm{ClO}_{4}{ }^{-}$dopant at this temperature is also reported in a previous work $^{10,11}$. The same process is not detectable in the $\mathrm{BF}_{4}{ }^{-}$ doped polymer at $200{ }^{\circ} \mathrm{C}$. The temperature was not in-

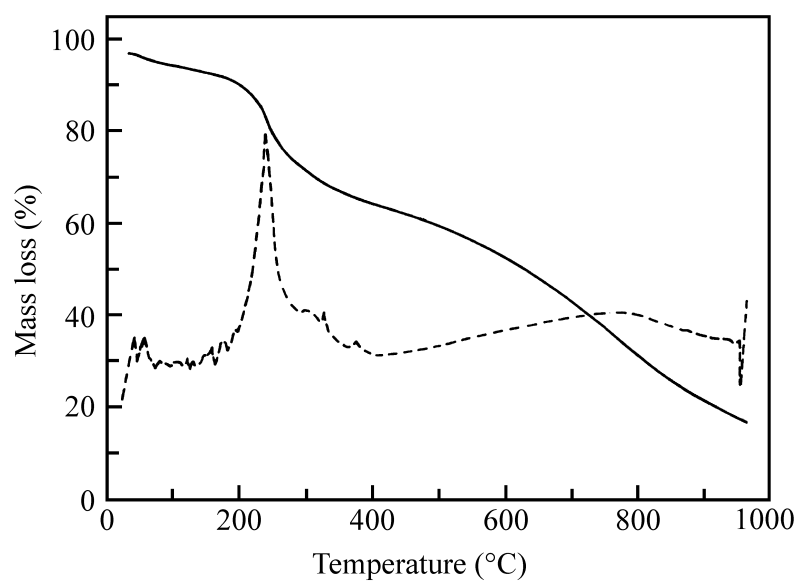

Figure 3. Thermogravimetric analysis of a powder sample of pure $\mathrm{pDP}\left(\mathrm{ClO}_{4}{ }^{-}\right.$as counterion) under Ar flow; broken line is the first derivative of the TGA curve. Heating rate $=10^{\circ} \mathrm{C} \mathrm{min}^{-1}$.

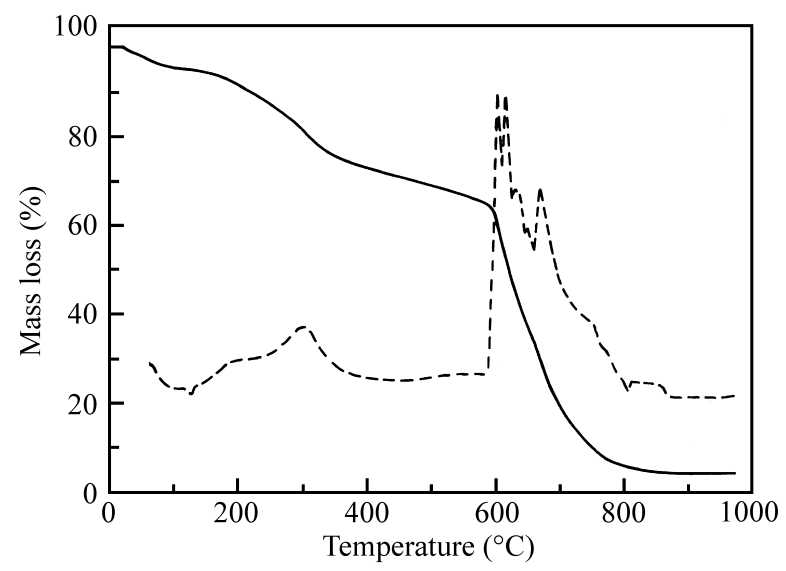

Figure 4. Thermogravimetric analysis of a powder sample of pure $\mathrm{pDP}\left(\mathrm{BF}_{4}{ }^{-}\right.$as counterion) under the same conditions as Fig. 3; broken line is the first derivative of the TGA curve.

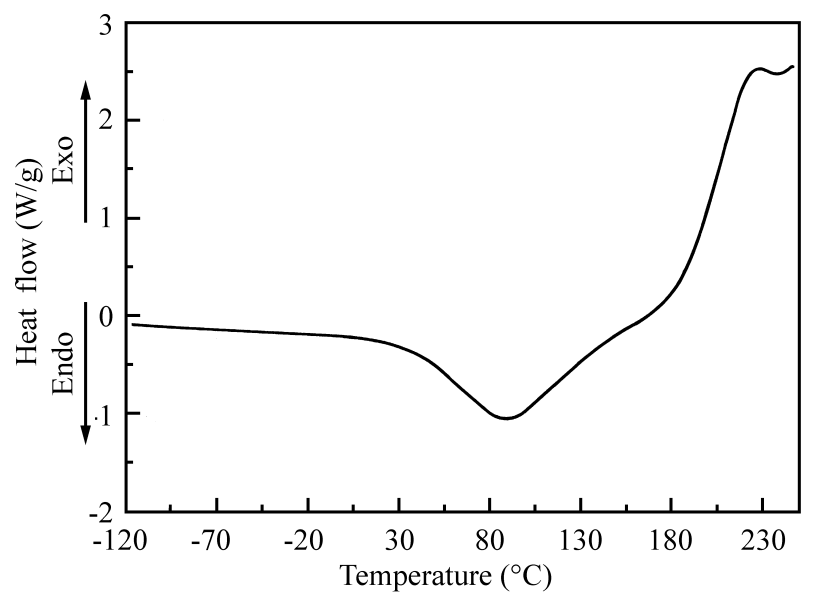

Figure 5. DSC measurement under $\mathrm{Ar}$ flow for $\mathrm{pDP}\left(\mathrm{ClO}_{4}{ }^{-}\right.$as counterion) powder. Heating rate $=10{ }^{\circ} \mathrm{C} \mathrm{min}-1$. 
creased over this value because of sample decomposition. In this case, it is possible that the exothermic process related to the counterion loss occurs at higher temperatures. No other thermal processes were detected in the range of $-120{ }^{\circ} \mathrm{C}$ to $200{ }^{\circ} \mathrm{C}$; this is evidence of the amorphous nature of the material.

Observations by optical and electron scanning microscopy of the products of the electropolymerisation of dithienopyrrole on PVC coated electrodes also give evidence for composite formation. These experiments suggest that the polymerisation of dithienopyrrole occurs at the interface between the solution and the PVC film, and along a number of pores created by the solvent swelling into the host polymer. When the electro-oxidation proceeds, $\mathrm{pDP}$ gradually fills these pores, and goes out from the polymer film at the side opposite to the electrode in the form of amorphous aggregates, as shown in the scanning electron micrography in Fig. 6. The distribution of pDP into the host polymer is uniform, as observed by optical microscopy (not shown in this paper). A further indication that the electropolymerization of $\mathrm{pDP}$ in PVC gives rise to a polymeric composite can be drawn by the observation of the electrochromic behaviour of the product. This is very similar to that of pure pDP, reported previously ${ }^{7}$. Also, the FTIR spectrum of the composite resembles a superposition of the spectra of its single components.

\section{Conclusions}

The product of electropolymerization of dithienopyrrole on an electrode coated with a PVC film is a polymeric composite. Moreover, while the electrochemical polymerization of dithienopyrrole do not give good electrodic films, the films of the composite are adherent and self supported. The conducting polymer grows from

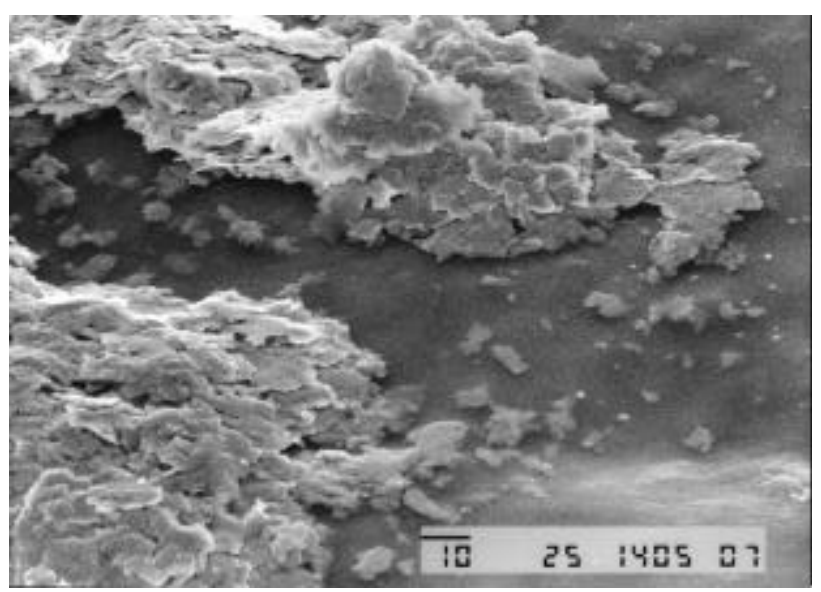

Figure 6. Scanning electro micrography (magnification of 750 times) of the surface opposite to the ITO electrode for the PVC-pDP composite produced after 5 potentiodynamic cycles at $0.100 \mathrm{~V} \mathrm{~s}^{-1}$ in a 0.1 M TBAP/acetonitrile solution contanining $10 \mathrm{mM}$ dithienopyrrole. the electrode in the direction of the electrolyte and across the insulating polymer film. Adjusting the polymerization time, the pDP film reaches the side opposite to the electrode for a PVC thickness of 2-3 $\mu \mathrm{m}$. Microscopic observations suggest the formation of aggregates of conducting polymer into the PVC "sponge", with an homogeneous distribution of pDP into the host polymer. The electrical conductivity of these films $\left(0.6 \mathrm{~S} \mathrm{~cm}^{-1}\right)$ is not much lower than that for pure $\mathrm{pDP}^{6,7}$. Pure $\mathrm{pDP}$ shows no mass loss during heating up to $200{ }^{\circ} \mathrm{C}$. Above this temperature the thermogravimetric measurements reveal polymer dedoping. Chain decomposition occurs at $600{ }^{\circ} \mathrm{C}$. DSC measurements do not show phase transitions for pure $\mathrm{pDP}$. This may indicate a very low degree of crystallinity for pDP. Finally, the above results indicate that the production of a composite material of a thermoplastic polymer and electrochromic pDP was achieved. The process yields a self-supported and adherent electrochromic polymeric material.

\section{Acknowledgments}

This work was developed with the support of the exchange programm between Conselho Nacional de Desenvolvimento Científico e Tecnológico (CNPq-Brazil) and Consiglio Nazionale delle Ricerche (CNR-Italy).

\section{References}

1. Heeger, A.J.; Smith, P. Solution Processing of Conducting Polymers, In Conjugated Polymers; Brédas, J.L.; Silbey, R., Eds.; Kluwer Academic Publishers, Dordrecht, 1991 , p.141.

2. a) De Paoli, M.-A.; Waltman, R.J.; Diaz, A.F.; J. Polym. Sci., Polym. Chem. Ed. 1985, 23, 1687. b) Matencio, T. Mano, V. Felisberti M.I.; De Paoli, M.-A. Electrochim. Acta 1994, 39, 1393.

3. a)Zoppi, R.A.; De Paoli, M.-A. J. Electroanal. Chem. 1990, 290, 275. b) Tassi, E.L.; De Paoli, M.-A. Polymer 1992, 33, 2427.

4. Zoppi, R.A.; Felisberti, M.I.; De Paoli,M.-A. J. Polym. Sci.: Part A: Polym. Chem. 1994, 32, 1001.

5. De Paoli, M.-A. Conductive polymer blends and composites", in Organic conductive molecules and polymers; Nalwa, H.S., Ed.; John Wiley, New York, 1997.

6. Casalbore-Miceli, G.; Beggiato, G.; Geri, A.; Berlin, A.; Pagani, G.; Zotti, G.; De Paoli, M.-A. Mol. Cryst. Liq. Cryst. 1992, 219, 173.

7. Berlin, A.; Pagani, G.; Zotti, G.; Schiavon, G. Makromol. Chem. 1992, 193, 399.

8. Zanirato, P.; Spagnolo, P.; Zanardi, G. J. Chem. Soc., Perkin Trans. 1983, 1, 2551.

9. Beggiato, G.; Casalbore-Miceli, G.; Fattori, V.; Geri, A.; Berlin, A.; Zotti, G. Synth. Met. 1993, 55, 3495. 
10. Giro, G.; Casalbore-Miceli, G.; Pezzoli, M.; Ceccorulli, G. Synth. Met. 1992, 47, 133.
11. Boyle, A.; Penneau, J.F.; Genies, E.M.; Riekel, C. J. Polym. Sci.: Part B: Polym. Phys. 1992, 30, 265.

FAPESP helped in meeting the publication costs of this article 